\title{
Hot-Workability of IN706 Alloy
}

\author{
Zhengdong Long Diangxia Fu Peili Ma Zengyong Zhong \\ Superalloy Department, Central Iron \& Steel Research Institute \\ Beijing ,P. R. China
}

\begin{abstract}
The pattern of hot-deformation of IN 706 alloy at different temperature and true strain rate was studied in this paper. It shows that this alloy has excellent hot - workability from $900^{\circ} \mathrm{C}$ to $1100^{\circ} \mathrm{C}$. The true stress decreases with increasing temperature and increases with increasing true strain rate. Because of dynamic recrystallization during hot deformation, a turning point appears on the curves of true stress with temperature and true strain rate.
\end{abstract}

\section{Introduction}

IN706 alloy, a nickel - iron base superalloy, has excellent mechanical properties and workability. With the development of high power gas turbines, there is a great demand for large size superalloy products [1]. Many conferences on the metallurgy of this alloy have been hold $[2-4]$, however there is less systematic research on the behaviour and regularity of hot - deformation. So the hot - workability, the true stress changement under different conditions, deformation active energy and hot deformation formula were studied in this paper.

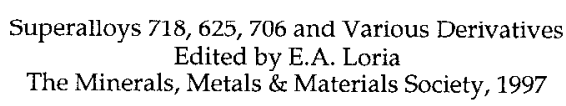




\section{$\underline{\text { Experimental Method }}$}

A cast spheroid of $140 \mathrm{~mm}$ diameter ingot was melted by VIM (vacuum induction melting) and the principal chemical elements are given in Table 1 . The specimens were cut off from the fringe and machined to $8 \mathrm{~mm}$ diameter $\times 10 \mathrm{~mm}$ height. The temperature, true strain rate and true stress were measured by FORMASTER compresion testing machine. The specimen was heated by electric current. The range of testing temperatures is from $900{ }^{\circ} \mathrm{C}$ to $1100^{\circ} \mathrm{C}$ and that of true strain rate is $5.0 \times 10^{-4}$ to $1.0 \mathrm{~S}^{-1}$.

Table 1 The chemical composition of IN706 alloy (wt \%)

\begin{tabular}{ccccccc}
\hline $\mathrm{C}$ & $\mathrm{Cr}$ & $\mathrm{A} 1$ & $\mathrm{Ni}$ & $\mathrm{Nb}$ & $\mathrm{B}$ & $\mathrm{Fe}$ \\
\hline 0.016 & 16 & 0.19 & 42 & 3.18 & 0.004 & balance \\
\hline
\end{tabular}

\section{$\underline{\text { Rcsults and Disscusion }}$}

\section{True Stress Change During Hot Deformation}

The relation between true stress and temperature at the strain rate of $1.0 \times 10^{-2} \mathrm{~S}^{-1}$ is shown in Figure 1. It shows that, with increasing true strain, the true stress increases first but soon becomes essentially stable after a certain strain value. This result is consistent with other materials. The following equation is proposed to evaluate these relations among temperature, true strain rate and true stress.

$$
\sigma=\left[\frac{1}{\mathrm{~A}} \dot{\varepsilon} \exp \left(\frac{\mathrm{Q}}{\mathrm{RT}}\right)\right]^{1 / \mathrm{n}}
$$

Where $\mathrm{A}$ is a constant, $\mathrm{n}$ is the true strain rate determined strengthing parameter, $\dot{\varepsilon}$ is true strain rate, $\sigma$ is the stable true stress, $Q$ is deformation active energy, $R$ is a constant. From this equation the following relations could be obtained.

$$
Q=R \cdot n \cdot\left[\frac{\partial \ln \sigma}{\partial(1 / T)}\right]_{:} \quad n=\left(\frac{\partial \ln \dot{\varepsilon}}{\partial \ln \sigma}\right)_{T}
$$

From the above analysis, it seems that the $1 / \mathrm{T}$ and $\ln \sigma$ should have a linear relationship. The experimmental data of $1 / \mathrm{T}$ and $l n \sigma$ is given in Figure 2. It shows that the $1 / \mathrm{T}$ and Ino really have an approximate linear relationship, but there is a turning point that is obviously related with dynamic recrystallization during hot deformation. When the temperature is much lower than that point, deformation is very difficult to carry on even at the higher stress. However, when the temperature is much higher, the true stress is not decreased significantly. So the proposed hot deformation temperature is that point which in the case of IN 706 alloy is $1050^{\circ} \mathrm{C}$. 
The true stress vs true strain curves at $1050^{\circ} \mathrm{C}$ under different true strain rates are given in Figure 3. They show that after having a certain true strain, the true stress will not increase with increasing true strain. From equation (2), we can see that the $\ln \sigma$ and $\ln \dot{\varepsilon}$ should have a linear relationship. Figure 4 gives the experimental data of $\ln \sigma$ and $\ln \dot{\varepsilon}$ under 0.2 true strain, and an approximmately linear relationship between $\ln \sigma$ and $\ln \dot{\varepsilon}$ really appears, but there is a turning point at $\ln \dot{\varepsilon}=-4.61 \mathrm{~S}^{-1}$. Above this point, There is a steeper slope than that below this point. It means that, when the true strain rate is greater than this point, the extent of increasing true stress is much greater, and this behaviour may be related with dynamic recrystallization. When the true strain rate is less than that point, there is enough time to complet the dynamic recrystallization, so it lowered the true stress obviously. However, when the true strain rate is greater than that point, There is not enough time to complete the dynamic recrystallization. So, the consequent rseult is, when the true strain rate is too great, the true stress is so much

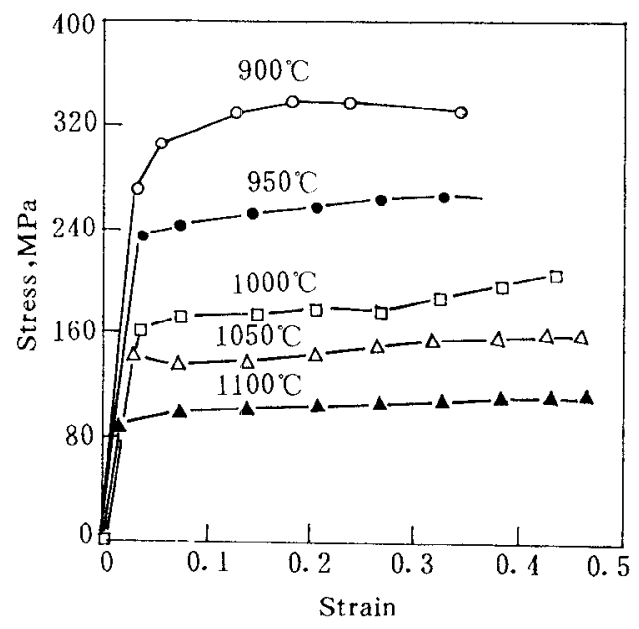

Fig. 1 Flow stress - strain of IN706 alloy under the strain rate of $1.0 \times 10^{2} \mathrm{~S}^{-1}$

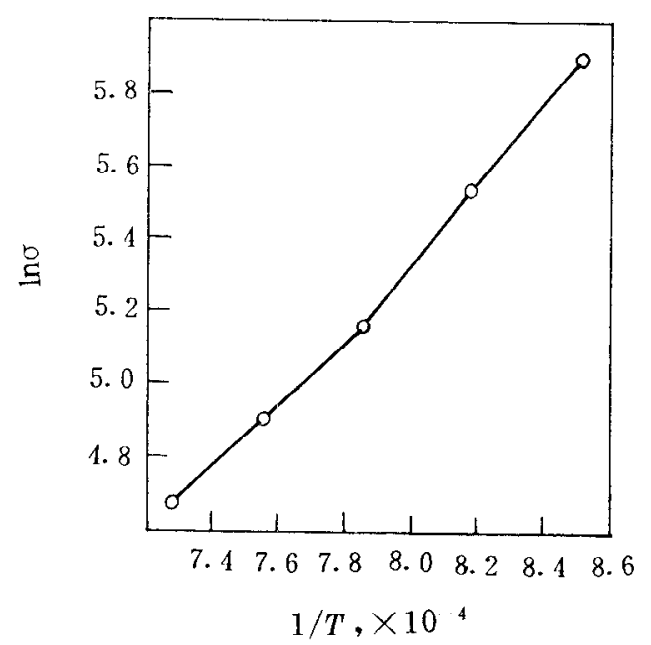

Fig. 2 Flow stress vs temperature at strain rate of $0.01 \mathrm{~S}^{-1}$ 


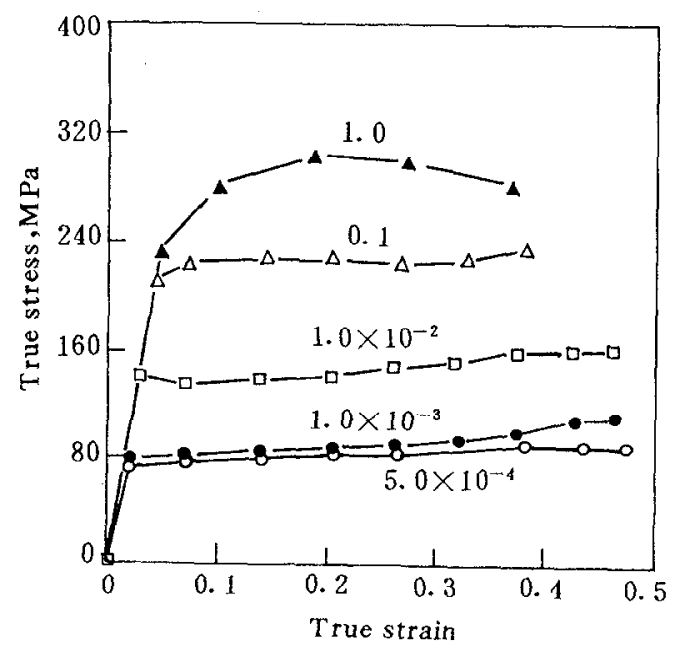

Fig. 3 Flow stress - strain of IN 706 alloy at $1050^{\circ} \mathrm{C}$

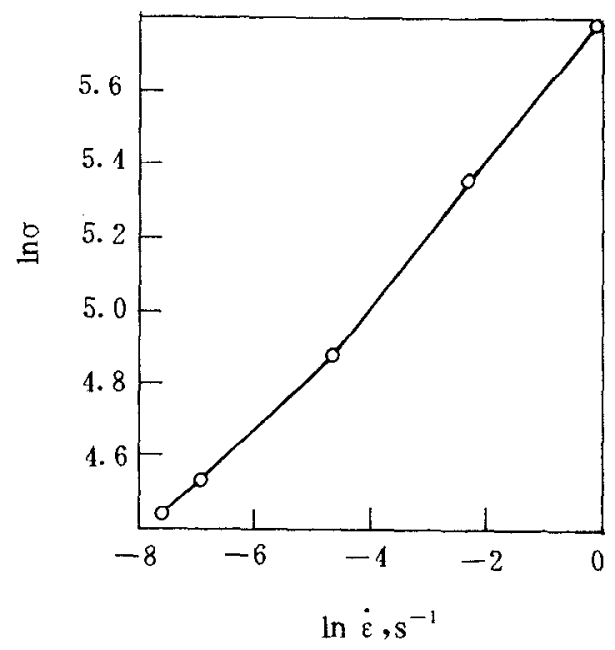

Fig. 4 Flow stress vs true strain rate at $1050^{\circ} \mathrm{C}$

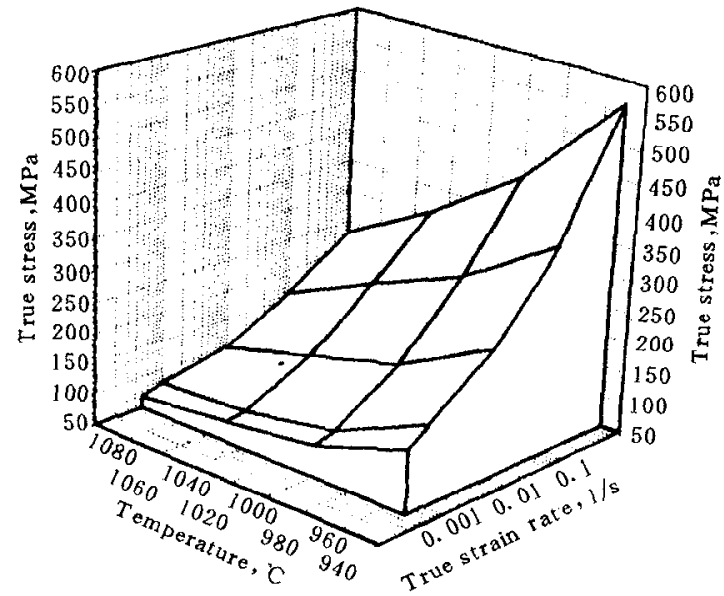

Fig. 5 Strain rate--temperature-stress figure of IN706 208 
higher that it makes the hot deformation very difficult to carry on, On the other hand, when the true strain rate is much lower than that point, the true stress will not decrease obviously and the time of deformation will be too long to have practical meaning. So practical hot deformation true strain rate should be select nearby this point (as for this alloy the point true strain rate is $\left.1.0 \times 10^{-2} \mathrm{~S}^{-1}\right)$. Figure 5 provides a 3 -dimension surface map in order to illustrate directly the relationships among temperature, true strain rate and true stress.

\section{The Foundation of Hot Deformation}

By utilizing the statistical method, the average values of $\mathrm{N}, \mathrm{Q}$ and $\mathrm{A}$ can be obtained from the slopes calculated in Figures 3 and 4.

$$
N=5.785 \quad Q=472 \mathrm{KJ} / \mathrm{mol} \quad A=20498
$$

So the formula was obtained as following:

$$
\sigma=0.1798\left[\dot{\varepsilon} \exp \left(\frac{56800}{T}\right)\right]^{0.173}
$$

where $\mathrm{T}$ is the absolute temperature.

In order to evaluate the correctness of this formula, Table 2 gives the comparison between calculated and tested data. So the great reliability of this formula is evident in this Table.

Table 2 Comparison between calculated and tested data (MPa)

\begin{tabular}{ccccccc}
\hline \multirow{2}{*}{ temperature $\left({ }^{\circ} \mathrm{C}\right)$} & \multicolumn{5}{c}{ true strain rate $\left(\mathrm{S}^{-1}\right)$} \\
\hline \multirow{2}{*}{950} & $\mathrm{~A}$ & 145 & 155 & 255 & 371 & 566 \\
& $\mathrm{~B}$ & 149 & 168 & 250 & 373 & 550 \\
\hline \multirow{2}{*}{1000} & $\mathrm{~A}$ & 100 & 111 & 177 & 266 & 410 \\
& $\mathrm{~B}$ & 109 & 123 & 182 & 272 & 404 \\
\hline \multirow{2}{*}{1050} & $\mathrm{~A}$ & 82 & 87 & 141 & 226 & 298 \\
& $\mathrm{~B}$ & 81 & 92 & 136 & 203 & 302 \\
\hline \multirow{2}{*}{1100} & $\mathrm{~A}$ & 62 & 65 & 101 & 150 & 220 \\
& $\mathrm{~B}$ & 62 & 70 & 104 & 155 & 231 \\
\hline
\end{tabular}

\footnotetext{
${ }^{*} \mathrm{~A}$ : tested data B:calculated data
} 


\section{Conclusions}

(1) IN706 alloy has excellent hot-workability between $900^{\circ} \mathrm{C}$ and $1100^{\circ} \mathrm{C}$

(2) Because of dynamic recrystallization during hot deformation, a turning point appears on the curves of true stress with temperature and true strain rate.

(3) The practical hot deformation temperature and true strain rate should be selected near the point at which the dynamic recrystallization is just about to occur.

(4) The hot deformatioin formula for IN706 alloy can be obtained from the following equation :

$$
\sigma=0.1798\left[\because \exp \left(\frac{56800}{T}\right)\right]^{0.173}
$$

\section{Conferences}

[1]Schilke P. W. , Pepe J. et al. , Alloy 706 Metallurgy and Turbine Wheel Application, International Special Emphasis Symposium on Superalloys 718, 625, 706 and Derivatives, Pittsburgh, PA, June, 1994,1.

[2]Moyer J. M. , Jackman L. A. , Adasczik C. B. , Davis R. M., Advances in Triple Melting Superalloys 718,706 and 720, International Special Emphasis Symposium on Superalloys 718,625,706 and Derivatives, Pittsburgh, PA ,June, 1994, 39.

[3] Grose S. M., The Vacuum Arc Remelting of Large Diameter Alloy 706, International Special Emphasis Symposium on Superalloys 718, 625, 706 and Derivatives, Pittsburgh, PA, June, 1994, 49.

[4]Thamboo S. V. ,Melt Related Defects in Alloy 706 and Their Effects on Mechanical Properties, International Special Emphasis Symposium on Superalloys 718,625, 706 and Derivatives, Pittsburgh, PA, June, 1994, 137. 